\title{
An evidence-based treatment algorithm for the management of WHO Grade II and III meningiomas
}

\author{
*Sam Q. Sun, BS, ${ }^{1}$ Ammar H. Hawasli, MD, PhD, ${ }^{2}$ Jiayi Huang, MD, ${ }^{3}$ Michael R. Chicoine, MD, ${ }^{2}$ \\ and Albert H. Kim, MD, PhD²
}

${ }^{1}$ Washington University School of Medicine; and Departments of ${ }^{2}$ Neurosurgery and ${ }^{3}$ Radiation Oncology, Washington University School of Medicine in St. Louis, Missouri

\begin{abstract}
The management of WHO Grade II "atypical" meningiomas (AMs) and Grade III "malignant" meningiomas (MMs) remains controversial and under-investigated in prospective studies. The roles of surgery, radiation therapy, radiosurgery, and chemotherapy have been incompletely delineated. This has left physicians to decipher how they should treat patients on a case-by-case basis. In this study, the authors review the English-language literature on the management and clinical outcomes associated with AMs and MMs diagnosed using the WHO 2000/2007 grading criteria. Twenty-two studies for AMs and 7 studies for MMs were examined in detail. The authors examined clinical decision points using the literature and concepts from evidence-based medicine. Acknowledging the retrospective nature of the studies concerning $\mathrm{AM}$ and $\mathrm{MM}$, the authors did find evidence for the following clinical strategies: 1) maximal safe resection of AM and $M M$; 2) active surveillance after gross-total resection of $A M$; 3) adjuvant radiation therapy after subtotal resection of AM, especially in the absence of putative radioresistant features; and 4) adjuvant radiation therapy after resection of MM.

http://thejns.org/doi/abs/10.3171/2015.1.FOCUS14757
\end{abstract}

KEY WORDS meningioma; atypical meningioma; anaplastic meningioma; malignant meningioma

$\mathrm{M}$ ENINGIOMAS are the most common primary brain tumor in adults. One-third consist of atypical (WHO Grade II) and malignant (WHO Grade III) meningiomas (herein referred to as AMs and MMs, respectively). ${ }^{19,20,60}$ These nonbenign tumors have been the subject of considerable recent literature. However, because of the lack of randomized controlled trials, several controversies regarding the optimal management of these lesions remain unresolved. In particular, many have suggested that the 2000 and 2007 revisions to the WHO classification scheme for brain tumors dramatically changed the makeup of "Grade II" and "Grade III" meningiomas (Table 1), ${ }^{43,44,47}$ with significant implications for their management. $3,17,60,73,83,85$

The 2000/2007 WHO classification scheme is more objective regarding the definitions of AM and MM, and, hence, there is significantly less variation in interpretation. ${ }^{5,17}$ AMs are defined as meningiomas with 1 or more of the following: 1) 4-19 mitoses per $10 \mathrm{hpf}$; 2) at least 3 of the following 5 atypical features: spontaneous necrosis, macronucleoli, loss of architecture (sheeting), hypercellularity, and small cell change; 3) brain invasion; or 4) predominant ( $>50 \%$ of the tumor volume) clear-cell or chordoid morphology. ${ }^{47} \mathrm{MMs}$ are defined as meningiomas with either 20 or more mitoses per $10 \mathrm{hpf}$, or predominant rhabdoid or papillary morphology. ${ }^{47}$ We report a comprehensive review of the literature on management of Grade II and III meningiomas based on WHO 2000/2007 criteria and attempt to define optimal treatment strategies for these tumors given the most current evidence.

\section{Methods \\ Article Selection}

Using the PubMed and Google Scholar search engines, we performed searches of the English-language literature between 2000 and 2014 using combinations of the terms atypical, anaplastic, malignant, Grade II, and Grade III

\footnotetext{
ABBREVIATIONS AM = Grade II meningioma (atypical meningioma); EBM = evidence-based medicine; EBRT = external beam radiation therapy; EGFR = epidermal growth factor receptor; EOR = extent of resection; GTR = gross-total resection; LC = local control; MM = Grade III meningioma (malignant meningioma); NTR = near-total resection; OS = overall survival; PDGFR = platelet-derived growth factor receptor; PFS = progression-free survival; RTK = receptor tyrosine kinase; SRS = stereotactic radiosurgery STR = subtotal resection; VGFR = vascular endothelial growth factor receptor.

SUBMITTED November 1, 2014. ACCEPTED January 8, 2015.

INCLUDE WHEN CITING DOI: 10.3171/2015.1.FOCUS14757.

DISCLOSURE The authors report no conflict of interest concerning the materials or methods used in this study or the findings specified in this paper. S.Q. Sun received educational funding from the American Brain Tumor Association Medical Student Summer Fellowship Supported by Dropping the Puck on Cancer at Indiana University.

* Mr. Sun and Dr. Hawasli contributed equally to this work.
} 
Table 1. WHO classification schemes for Grade II meningiomas (AMs) and Grade III meningiomas (MMs) by year

\begin{tabular}{|c|c|c|}
\hline Year of WHO Classification & AMs & MMs \\
\hline 1993 & $\begin{array}{l}\text { Several of: } \\
\text { - Frequent mitoses } \\
\text { - Increased cellularity } \\
\text { - Small cell change } \\
\text { - Prominent nucleoli } \\
\text { - Patternless or sheet-like growth }\end{array}$ & $\begin{array}{l}\text { Histological features of frank malignancy far in excess of } \\
\text { the abnormalities noted in atypical meningiomas, or } \\
\text { Brain invasive }\end{array}$ \\
\hline 2000 & $\begin{array}{l}\geq 4 \text { mitoses per } 10 \mathrm{hpf} \text {, or } \\
\geq 3 \text { of: } \\
\text { - Increased cellularity } \\
\text { - Small cell change } \\
\text { - Prominent nucleoli } \\
\text { - Patternless or sheet-like growth } \\
\text { - Foci of "spontaneous" or "geographic" necrosis }\end{array}$ & $\begin{array}{l}\geq 20 \text { mitoses per } 10 \mathrm{hpf} \text {, or } \\
\text { Anaplastic (malignant) cytology resembling that of carci- } \\
\quad \text { noma, melanoma, or high-grade sarcoma }\end{array}$ \\
\hline 2007 & $\begin{array}{l}\geq 4 \text { mitoses per } 10 \text { hpf, or } \\
\geq 3 \text { of: } \\
\text { - Increased cellularity } \\
\text { - Small cell change } \\
\text { - Prominent nucleoli } \\
\text { - Patternless or sheet-like growth } \\
\text { - Foci of "spontaneous" or "geographic" necrosis, or } \\
\text { Brain invasive, or } \\
\text { Predominant chordoid or clear cell morphology }\end{array}$ & $\begin{array}{l}\geq 20 \text { mitoses per } 10 \text { high-power fields (HPFs), or } \\
\text { Anaplastic (malignant) cytology resembling that of carci- } \\
\text { noma, melanoma, or high-grade sarcoma, or } \\
\text { Predominant papillary or rhabdoid morphology }\end{array}$ \\
\hline
\end{tabular}

with the term meningioma/meningiomas. To meet the inclusion criteria for this study, each article must have reported separate outcomes for Grade II versus Grade III meningiomas and have referenced the WHO 2000 or 2007 classification scheme for meningiomas. Importantly, only articles that included meningiomas graded according to the WHO 2000/2007 system were included in this study. The WHO 2000 and WHO 2007 systems for Grade II and III meningiomas are identical, except that in the latter, "brain invasion" is an independent criterion for the Grade II designation. Twenty-two studies for AMs and 7 studies for MMs met the final inclusion criteria.

\section{Article Analysis}

Local control (LC) and progression-free survival (PFS) values were obtained from each article where available. If LC and PFS were not in the text, they were extracted from survival curves using DigitizeIt software (http://www. digitizeit.de/). Published data were summarized into levels of evidence and grades of recommendation based on evidence-based medicine (EBM) systems. ${ }^{64,71,84}$ In brief, the grade of recommendation (1 or 2 ) refers to the clarity of risk/benefit, whereas the level of evidence $(\mathrm{A}-\mathrm{E})$ refers to the study design that a given recommendation is based on. Recommendations were aggregated to create a complete treatment algorithm for AM and MM.

\section{Results}

\section{WHO Grade II Meningiomas}

\section{Surgical Management}

Studies of WHO Grade II or AMs often report outcomes following surgery, since WHO histological grad- ing is not possible without biopsy or resection. However, we recognize that observation in the appropriate clinical context is a reasonable strategy for dural-based tumors of unknown grade that are small and asymptomatic and do not show evidence of growth on repeat imaging. ${ }^{10,54,86}$

For biopsy-proven AMs, maximal extent of resection (EOR) has been associated with improved long-term outcomes (Table 2). Recent retrospective studies corroborate the importance of gross-total resection (GTR) or Simpson Grade I-III resection for AMs. The 5-year PFS after GTR is $59 \%-90 \%$ but the 5-year PFS after subtotal resection (STR) is only $30 \%-70 \%$ (Table 2)..$^{13,24,26,46,48,59,77,78,81,85,87}$ For each of these studies, GTR shows a significant benefit over STR or Simpson Grade IV resection for AMs (EBM Level 3, Grade 1C recommendation). However, "maximal safe resection" may be a more appropriate strategy than GTR, given the surgical morbidity associated with resection in certain locations (e.g., cavernous sinus). ${ }^{72,75}$ Hence, while GTR is the goal, STR may be considered in select patients through traditional open surgery or minimally invasive techniques. ${ }^{28,36}$ It is unknown whether STR improves outcomes compared with biopsy alone.

Although the benefit of GTR versus STR is well established for AMs, the benefit of obtaining Simpson Grade I versus Grade II-III resection is less clear. Indeed, this is even a controversy for benign meningiomas (WHO Grade I). For benign meningiomas, some authors reported that Simpson Grade I-III resection yielded equivalent results, ${ }^{31,58,74}$ while others have advocated for Simpson Grade I or even more radical resection. ${ }^{28,42,79}$ This issue becomes even more ambiguous for AMs. Hammouche et al. reported a 5-year PFS of 74\% after Simpson Grade I resection of AMs but only 34\% after Simpson Grade II resection. ${ }^{24}$ These data are in opposition to 2 of the largest 
TABLE 2. Literature review of reported outcomes after GTR and STR of Grade II meningiomas

\begin{tabular}{|c|c|c|c|c|c|c|}
\hline Authors \& Year & $\begin{array}{l}\text { No. of } \\
\text { Cases }\end{array}$ & $\begin{array}{l}\text { Simpson Grade(s) } \\
\text { Corresponding to GTR }\end{array}$ & $\begin{array}{l}\text { GTR Cases } \\
(\%)\end{array}$ & $\begin{array}{c}\text { Outcomes After } \\
\text { GTR }\end{array}$ & $\begin{array}{l}\text { Outcomes After } \\
\text { STR }\end{array}$ & Benefit of GTR \\
\hline Yang et al., 2008 & 40 & $|-| \mid$ & $24(60)$ & NA & NA & OR $0.416 ; p=0.012$ (PFS) \\
\hline Mair et al., 2011 & 114 & $|-| \mid$ & $66(73)$ & $59 \%$ 5-yr PFS & $32 \%$ 5-yr PFS & HR 0.396; $p=0.018$ \\
\hline Lee et al., 2013 & 90 & $|-|||$ & $71(79)$ & $85 \%$ 5-yr PFS & $70 \%$ 5-yr PFS & HR 0.188; $p=0.007$ \\
\hline Park et al., 2013 & 83 & $|-| \mid$ & $55(66)$ & $59 \% 5-y r$ PFS & $30 \% 5$-yr PFS & $p=0.002$ \\
\hline Hardesty et al., 2013 & 258 & $|-| \mid$ & $149(58)$ & $85 \% 5-y r$ PFS & $54 \% 5-y r$ PFS & RR $0.255 ; p<0.0001$ \\
\hline Choi et al., 2014 & 72 & $|-| \mid$ & $53(74)$ & $92 \% 5-y r$ OS* & $61 \% 5-\mathrm{yr}$ OS* & HR 0.108; $p<0.001^{*}$ \\
\hline Hammouche et al., 2014 & 79 & I & $34(43)$ & $74 \%$ 5-yr PFS & $32 \%$ 5-yr PFS & HR 0.45;† $p=0.005$ \\
\hline Zhao et al., 2015 & 89 & $|-| \mid$ & $72(81)$ & NA & NA & HR 0.165; $p=0.021$ (OS) \\
\hline Sun et al., $2014^{77,78}$ & 210 & $|-|||$ & $151(72)$ & $89 \%$ 5-yr PFS & $48 \%$ 5-yr PFS & HR $0.169 ; p<0.001$ \\
\hline Wang et al., 2015 & 28 & NA & $14(50)$ & $90 \%$ 3-yr PFS & $38 \%$ 3-yr PFS & $p=0.005$ \\
\hline
\end{tabular}

$\mathrm{HR}=$ hazard ratio; $\mathrm{NA}=$ not available; $\mathrm{OR}=$ odds ratio; $\mathrm{RR}=$ relative risk.

* Combined WHO Grade II and III meningiomas.

† Per Simpson grade.

studies on AMs that reported 5-year PFS rates of $85 \%$ and $89 \%$ after Simpson Grade I-II or I-III resection for AMs, respectively, ${ }^{26,78}$ suggesting that complete excision of dura may be less important than complete excision of tumor alone for AMs. Most surgeons, however, including the senior authors of this study, would favor Simpson Grade I resection, if surgically feasible with little to no additional morbidity.

\section{Adjuvant EBRT After GTR}

The use of adjuvant external beam radiation therapy (EBRT) following GTR for AM is the subject of considerable debate..$^{34,41,49}$ Three retrospective studies advocated the use of adjuvant EBRT after GTR of AM (Table 3). 2,3,45 These studies reported improved LC or a trend toward improved LC with adjuvant EBRT and GTR versus GTR alone $(\mathrm{p}=0.04, \mathrm{p}=0.09$, and $\mathrm{p}=0.10$; Table 3$)$, although none reported PFS outcomes. These studies have 2 limitations. First, they include to varying degrees AMs diagnosed according to the 1993 WHO system, which have been shown to respond differently to EBRT compared with AMs diagnosed according to the 2000/2007 WHO system. ${ }^{3,17}$ Second, in 2 of these studies, no patient with an AM undergoing EBRT has a follow-up time longer than 7.5 years. ${ }^{2,45}$ Hardesty et al. and Sun et al. reported that AMs can recur over 10 years after initial treatment with or without adjuvant EBRT. ${ }^{26,78}$ Therefore, it is possible that these studies may not capture late recurrences for patients treated with adjuvant EBRT.

On the other hand, 10 retrospective studies consisting only of AMs diagnosed according to WHO 2000/2007 guidelines recommended active surveillance without rou-

TABLE 3. Literature review of retrospective studies assessing the role of adjuvant EBRT for WHO Grade II meningiomas following GTR*

\begin{tabular}{|c|c|c|c|c|c|c|}
\hline Authors \& Year & $\begin{array}{c}\text { No. of } \\
\text { Patients }\end{array}$ & $\begin{array}{l}\text { Median Follow-Up } \\
\text { Time (mos) }\end{array}$ & $\begin{array}{l}\text { Adjuvant EBRT } \\
\text { Patients }\end{array}$ & $\begin{array}{c}\text { Outcomes After } \\
\text { GTR Only }\end{array}$ & $\begin{array}{c}\text { Outcomes After } \\
\text { GTR+EBRT }\end{array}$ & Effect of Adjuvant EBRT \\
\hline Yang et al., 2008 & 24 & 58 & NR & NR & NR & None (PFS)† \\
\hline Jo et al., $2010 \ddagger$ & 11 & 40 & $5(45)$ & $100 \%$ 3-yr PFS & $100 \%$ 3-yr PFS & None† \\
\hline Mair et al., 2011 & 66 & NR & $15(23)$ & NR & NR & None (PFS)† \\
\hline Lee et al., 2013 & 71 & 49 & $17(24)$ & $65 \%$ 5-yr PFS & $74 \%$ 5-yr PFS & None, $p=1.00$ \\
\hline Park et al., 2013 & 55 & 43 & $17(31)$ & $65 \%$ 5-yr PFS & $52 \%$ 5-yr PFS & None, $p=0.86$ \\
\hline Hardesty et al., 2013 & 149 & 52 & $15(10)$ & 96\% 5-yr PFS & $100 \%$ 5-yr PFS & None† \\
\hline Hammouche et al., 2014 & 34 & 50 & $9(26)$ & 67\% 5-yr PFS & $100 \%$ 5-yr PFS & None, $p=0.13$ \\
\hline Choi et al., 2014 $\ddagger$ & 53 & 56 & $42(79)$ & NR & NR & None, $p=0.28(\mathrm{LC})$ \\
\hline Sun et al., 201478 & 151 & 45 & $37(25)$ & 91\% 5-yr LC & $100 \%$ 5-yr LC & None, $p=0.53$ \\
\hline Wang et al., 2015 & 14 & 57 & $3(21)$ & 87\% 3-yr PFS & $100 \%$ 3-yr PFS & None, $p=0.18$ \\
\hline Aghi et al., 2009 & 108 & 39 & $8(7)$ & $57 \%$ 5-yr LC & $100 \% 5-y r$ LC & Trend to benefit, $p=0.10$ \\
\hline Komotar et al., 2012 & 45 & 44 & $13(29)$ & $47 \%$ 5-yr LC & 78\% 5-yr LC & Trend to benefit, $p=0.09$ \\
\hline Aizer et al., 2014 & 68 & 59 & $18(26)$ & $68 \% 5-y r$ LC & $83 \% 5-y r$ LC & Benefit, $p=0.04$ \\
\hline
\end{tabular}

$\mathrm{NR}=$ not reported.

* Shaded studies included patients who were diagnosed using pre-2000 WHO guidelines. Studies that did not use the 2000/2007 WHO guidelines were excluded.

$\dagger p$ value not explicitly reported.

$\ddagger$ Data reported from the same institution. 
tine adjuvant EBRT after GTR (Table 3). ${ }^{13,24,26,37,46,48,59,78 \text {, }}$ ${ }^{81,85}$ Eight of these 10 studies did not detect any significant improvement in PFS with adjuvant EBRT, and the remaining 2 studies did not detect any significant improvement in LC. The discrepancy between these and the aforementioned 3 studies may in part be due to the categorization of less intrinsically aggressive or more radiation-resistant meningiomas as 2000/2007 WHO AMs compared with the 1993 WHO criteria. Together, although these 13 studies are limited by their retrospective nature, sample sizes, and nonrandom treatment assignments, the current literature overall does not favor the addition of adjuvant EBRT for AMs after GTR.

Complications of adjuvant EBRT should also be considered in clinical decision making. For example, Aghi et al. ${ }^{2}$ reported that although none of 8 patients receiving adjuvant EBRT suffered a recurrence, 1 patient developed radiation necrosis, which was subsequently treated with resection. In other studies on AMs, radiation necrosis occurred in $4.2 \%$ and $10.2 \%$ of patients. ${ }^{6,78}$ Without definitive evidence that EBRT reduces the risk of tumor recurrence and subsequent retreatment for all 2000/2007 WHO AMs, the risk of toxicity related to upfront EBRT needs to be carefully considered.

It is possible that some aggressive AMs may benefit from adjuvant EBRT. Independent prognostic factors for reduced time to recurrence after resection of 2000/2007 WHO AMs include elevated mitotic index (5 of 6 studies), ${ }^{37,46,57,78,80}$ elevated Ki 67 index (3 of 8 studies), ${ }^{8,80,81}$ brain invasion ( 2 of 4 studies), ${ }^{78,80}$ sheeting ( 1 of 3 studies), ${ }^{46}$ and histological necrosis (1 of 3 studies) ${ }^{46}$ Studies supporting adjuvant EBRT may be reporting on more aggressive AMs, which could account for their high recurrence rates after GTR $(27 \%-32 \%)$ and the trends toward improved LC with adjuvant EBRT. Interestingly, studies have shown that after controlling for EOR, a skull base location does not correlate with recurrence in AMs (8 of 8 studies), ${ }^{24,37,46,48,57,77,78,85}$ and therefore should not necessarily trigger a recommendation of adjuvant EBRT after GTR.

Results from studies (617 patients in total) relying solely on 2000/2007 WHO guidelines support active surveillance after GTR of AMs (EBM Level 3, Grade 1C recommendation). Multidisciplinary management is recommended for those AMs with particularly aggressive histological features. The current recommendation of active surveillance is certainly subject to revision pending results from the RTOG 0539/EORTC 1308 studies. ${ }^{67}$

\section{STR and Adjuvant EBRT}

In contrast to gross-totally resected AMs, adjuvant radiation therapy after STR of these tumors is generally accepted in the field. Five of 8 studies using 2000/2007 WHO guidelines demonstrated improved PFS after adjuvant EBRT (Table 4).24,26,37,46,48,59,77,81 However, Grade II meningiomas represent a heterogeneous group of tumors, ${ }^{47,51,53}$ and not all patients may benefit equally from adjuvant EBRT. ${ }^{24,26,77,85}$ In particular, histological necrosis has been shown to be a strong predictor of radioresistance in a large study by Sun et al. ${ }^{77}$ such that the efficacy of adjuvant EBRT may be limited in AMs with necrosis (EBM Level 3, Grade 2C recommendation). If supported by ad- ditional validation studies, necrosis may become a valuable biomarker with which to tailor treatment for patients. In addition, Yang et al. reported that brain invasion correlates with decreased PFS and OS after GTR/STR and adjuvant EBRT but not after resection alone. ${ }^{85}$ This finding's applicability to clinical decision making after STR is confounded by these authors' pooling of outcomes after GTR and STR. Overall, adjuvant EBRT is reasonable after STR (EBM Level 3, Grade 1C recommendation), but the results of STR and EBRT remain suboptimal, with a 5-year PFS of 43\%-91\%. Therefore, dose escalation of EBRT or novel approaches using radiosensitization should be investigated, especially for AMs with necrosis.

\section{Radiosurgery as an Adjuvant and Salvage Treatment}

There is abundant evidence for the use of stereotactic radiosurgery (SRS) as an effective alternative to surgery for newly diagnosed meningiomas that are presumably benign. ${ }^{18,69,70,75}$ However, it is unclear what role SRS plays in the treatment of AMs. A review of modern literature on SRS suggests that this modality can be effective for biopsy-proven AMs (Table 5).,12,18,25-27,50,61 In particular, adjuvant SRS following STR resulted in equivalent rates of long-term tumor control as adjuvant EBRT (EBM Level 3 , Grade $2 \mathrm{C}$ recommendation), ${ }^{26,77}$ although SRS tended to be used for smaller residual tumors in a smaller resection bed. ${ }^{77}$

SRS is also used as a salvage measure for AMs for which surgery and EBRT have failed ${ }^{41}$ Prior EBRT is known to be a negative predictor of outcome in patients undergoing SRS for AMs. ${ }^{12,61}$ Therefore, the true efficacy of SRS for AMs should be viewed in the context of radiation-naive versus nonradiation-naive AMs. Series that do not restrict analysis to radiation-naive AMs may therefore underestimate the LC and PFS afforded by SRS in the setting of radiation-naive AMs. Indeed, there is little to no difference between the 2 modalities for radiationnaive AMs as adjuvant therapy after STR ${ }^{26,77}$ or as salvage therapy after recurrence (S.Q. Sun and A.H. Kim, unpublished data). One caveat is that SRS would not be expected to affect microscopic disease in the entire resection bed, and therefore, treatment failures outside the radiosurgical target volume have been reported. ${ }^{40}$ In summary, EBRT and SRS are complementary strategies for management of AMs after STR or recurrence. One may be more appropriate depending on clinical circumstances, and, in particular, the volume of the residual or recurrent disease. Larger studies comparing these 2 radiation modalities are necessary.

\section{Chemotherapy}

Chemotherapy for AMs has been an active area of research for decades. Most studies have had limited scope, lacking control-cohort data, and the studies rarely separate outcomes for Grade II and Grade III meningiomas. As a whole, chemotherapy for AMs has had limited success. In a recent review of surgery- and radiation-refractory AMs and MMs treated with medical therapies, the weighted average PFS at 6 months was 26\% (95\% CI 19.3\%-32.7\%); ${ }^{38}$ stratification by Grade II versus III was not available because most studies pooled AMs and MMs together. Pa- 
TABLE 4. Literature review of retrospective studies assessing the role of adjuvant EBRT for WHO 2000/2007 Grade II meningiomas following STR

\begin{tabular}{lccccc}
\hline Authors \& Year & $\begin{array}{c}\text { No. of } \\
\text { Patients }\end{array}$ & $\begin{array}{c}\text { Patients w/ } \\
\text { Adjuvant EBRT }\end{array}$ & $\begin{array}{c}\text { 5-Yr PFS After } \\
\text { STR Only }\end{array}$ & $\begin{array}{c}\text { 5-Yr PFS After } \\
\text { STR + EBRT }\end{array}$ & $\begin{array}{c}\text { Improved PFS w/ } \\
\text { Adjuvant EBRT }\end{array}$ \\
\hline Jo et al., 2010 & 23 & 16 & $34 \%$ & $63 \%$ & Yes, $p=0.01$ \\
\hline Mair et al., 2011 & 48 & 15 & $14 \%$ & $43 \%$ & Yes, $p=0.04$ \\
\hline Hardesty et al., 2013 & $79^{*}$ & 20 & $60 \%$ & $80 \%$ & No, $p=0.55$ \\
\hline Park et al., 2013 & 25 & 7 & $0 \%$ & $68 \%$ & Yes, $p<0.001$ \\
\hline Lee et al., 2013 & 19 & 5 & $20 \%$ & $91 \%$ & Yes, $p=0.002$ \\
\hline Hammouche et al., 2014 & 45 & 27 & NR & NR & No, $p>0.34 \dagger$ \\
\hline Sun et al., 201477 & 59 & 25 & $30 \%$ & $65 \%$ & Yes, $p=0.03$ \\
\hline Wang et al., 2015 & 14 & 9 & $0 \%$ & $49 \%$ & No, $p=0.07$ \\
\hline
\end{tabular}

* May include patients with spinal meningiomas or syndromic meningiomas, as well as patients that had undergone previous tumor resection or EBRT at the site of the atypical meningiomas

$\dagger p$ value not explicitly reported.

tients with these refractory tumors typically have a median overall survival of only $6-33$ months. ${ }^{9,38,56}$

Modern trials have looked at the possible utility of receptor tyrosine kinase (RTK) inhibitors. Gefitinib, erlotinib, and imatinib, which target platelet-derived growth factor receptor (PDGFR) and epidermal growth factor receptor (EGFR), respectively, have generally been ineffective for AM and MM. ${ }^{56,66,82}$ Although imatinib in combination with hydroxyurea did achieve a modest effect in Grade II and III meningiomas with a 6-month PFS of $46 \%$, the 12 -month PFS was only $8 \% .{ }^{66}$ Several authors have suggested antiangiogenic agents for the treatment of AM and MM..$^{30,62,63}$ Agents that target vascular endothelial growth factor receptor (VEGFR) have had more success in recent Phase II trials. Vatalanib, an oral RTK inhibitor with activity against VEGFR1-3, achieved a 6-month PFS of $64 \%$ in AMs and $38 \%$ in Grade III meningio- mas. ${ }^{65}$ Sunitinib, an oral RTK inhibitor against VEGFR, PDGFR, and KIT, achieved a 6-month PFS of $42 \%$ in Grade II and III meningiomas. ${ }^{39}$ Agents against VEGFR and VEGF, including RTK inhibitors and bevacizumab, respectively, have demonstrated 6-month PFS rates of 42\%-64\% against AM and MM. ${ }^{39,65}$ This relative success must be tempered, however, by the high rate of side effects and the low median overall survival (OS) with chemotherapy for these surgery- and radiation-refractory Grade II and III meningiomas, at approximately 24 months. . $^{39,55,56,65}$ Chemotherapy for AMs shows promise but should only be considered for select refractory tumors as salvage therapy.

\section{Treatment Algorithm for AMs}

Based on the evolving literature and our institutional data of the treatment of these lesions, we suggest an algorithm for AM management (Fig. 1). Importantly, treatment

TABLE 5. Literature review of studies assessing the role of SRS or EBRT for residual or recurrent WHO 2000/2007 Grade II meningiomas*

\begin{tabular}{|c|c|c|c|c|c|c|}
\hline Authors \& Year & $\begin{array}{l}\text { Median Follow-Up } \\
\text { Time (mos) }\end{array}$ & $\begin{array}{c}\text { SRS } \\
\text { Cases }\end{array}$ & $\begin{array}{l}\text { Outcomes After } \\
\text { SRS }\end{array}$ & $\begin{array}{l}\text { EBRT } \\
\text { Cases }\end{array}$ & $\begin{array}{c}\text { Outcomes After } \\
\text { EBRT }\end{array}$ & $\begin{array}{l}\text { Difference After } \\
\text { SRS vs. EBRT }\end{array}$ \\
\hline Choi et al., 2010 & 22 & 20 & $54 \%$ 3-yr LC & 0 & - & - \\
\hline Pollock et al., 2012 & 38 & 18 & $\begin{array}{l}50 \% \text { 5-yr LC } \dagger \\
89 \% \text { 5-yr DFS } †\end{array}$ & 0 & - & - \\
\hline Hardesty et al., 2013 & 52 & 22 & $90 \% 5$-yr PFS & 20 & $80 \%$ PFS at 5 yrs & No, $p=0.52$ \\
\hline Sun et al., $2014^{77}$ & 67 & 7 & $67 \%$ 5-yr LC & 25 & $64 \%$ LC at 5 yrs & No, $p=0.30$ \\
\hline Harris et al., 2003 & 28 & 18 & $83 \%$ 5-yr PFS & 0 & - & - \\
\hline Mattozo et al., 2007 & 42 & $19 \ddagger$ & $100 \%$ 3-yr PFS & 5 & $33 \%$ PFS at 3 yrs & NR \\
\hline Kano et al., 2007 & 43 & $25 \S$ & 48\% 5-yr PFSף & 0 & - & - \\
\hline Attia et al., 2012 & 43 & $24^{* *}$ & $25 \%$ 5-yr PFS & 0 & - & - \\
\hline Hanakita et al., 2013 & 24 & $28+\dagger$ & $16 \%$ 5-yr LC & 0 & - & - \\
\hline \multicolumn{7}{|c|}{$\begin{array}{l}\text { DFS = disease-free survival; }-=\text { not applicable. } \\
\text { * Shaded studies included patients who were not uniformly radiation naive. } \\
\dagger \text { Includes } 1 \text { case of Grade III meningioma. } \\
\text { † Three cases received prior EBRT. } \\
\text { § Four cases received prior EBRT or SRS. } \\
\text { I Includes } 5 \text { cases of Grade III meningioma. } \\
\text { ** Eleven cases received prior EBRT. } \\
\dagger † \text { Nine cases received prior EBRT or SRS. }\end{array}$} \\
\hline
\end{tabular}




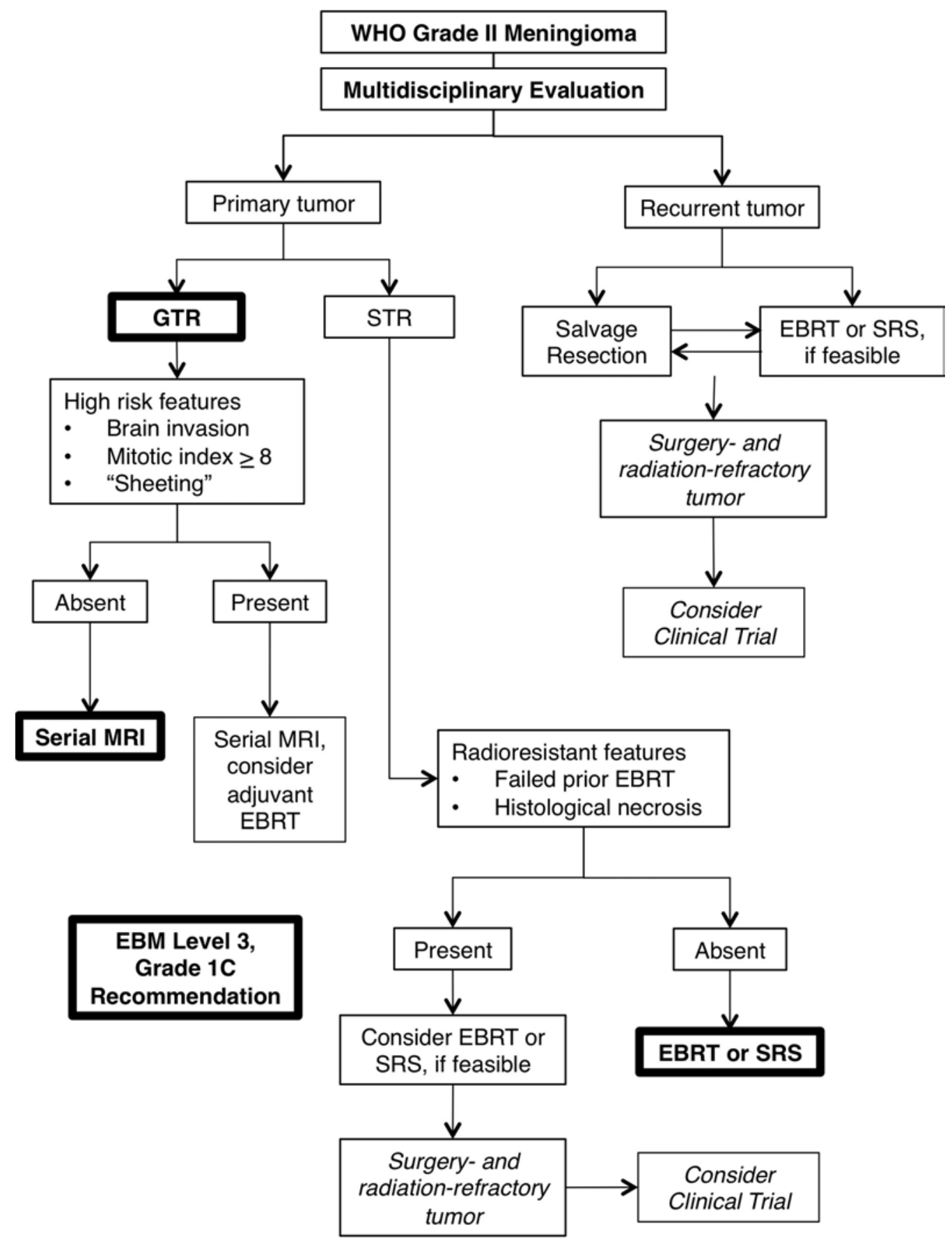

FIG. 1. Suggested algorithm for treatment of WHO Grade II meningiomas. Treatment options in bold represent EBM Level 3 , Grade $1 \mathrm{C}$ recommendations.

of neurooncology patients is a multidisciplinary endeavor and requires input from all teams involved, including but not limited to surgeons, radiation and medical oncologists, neuropathologists, and neuroradiologists. The algorithm attempts to summarize key findings in the literature while allowing considerable room for clinical decision making. For recurrent AMs, fewer evidence-based recommendations can be made based on available literature. In particular, no studies of WHO 2000/2007 AMs compare outcomes of salvage resection against salvage EBRT or SRS for recurrent AMs; for these tumors, we recommend tailoring treatment to the specific clinical scenario. In our experience, salvage resection is considered if the recurrent AM is accessible, salvage SRS is considered if the recurrent AM is relatively small and localized, and salvage EBRT is considered if the recurrent AM is radiation-naive and of a relatively larger volume such that SRS is not feasible.

\section{WHO Grade III Meningiomas}

Prior to the 2000/2007 WHO grading changes, MMs 
Management of WHO Grade II and III meningiomas

TABLE 6. Literature review of studies assessing the role of surgery and radiation therapy for WHO 2000/2007 Grade III meningiomas*

\begin{tabular}{|c|c|c|c|c|}
\hline Authors \& Year & $\begin{array}{c}\text { No. of } \\
\text { Patients }\end{array}$ & Treatments & Outcomes & Improved Outcomes With Adjuvant EBRT \\
\hline Durand et al., 2009 & 33 & GTR/STR \pm Adjuvant EBRT & $8 \% 5-y r$ PFS & Benefit: $p=0.18$ for PFS; $p=0.036$ for $O S$ \\
\hline Rosenberg et al., 2009 & 13 & GTR/STR \pm Adjuvant EBRT & 9\% 3-yr PFS; 47\% 5-yr OS & Trend to benefit; $p$ values NR \\
\hline Sughrue et al., $2010^{76}$ & 34 & GTR/STR+Adjuvant EBRT & $57 \%$ 5-yr PFS; $61 \%$ 5-yr OS & \\
\hline Adeberg et al., 2012 & 23 & GTR/STR+Adjuvant EBRT & $15 \%$ 5-yr PFS; $53 \%$ 5-yr OS & \\
\hline Pollock et al., 2012 & 13 & Salvage SRS & $27 \% 5$-yr DFS & \\
\hline Ferraro et al., 2014 & 4 & GTR/STR+SRS & 0\% 3-yr PFS; 33\% 3-yr OS & \\
\hline Zhao et al., 2015 & 37 & GTR/STR \pm Adjuvant EBRT & $12 \% 5$-yr PFS & Benefit: $p=0.039$ for PFS; $p=0.006$ for OS \\
\hline
\end{tabular}

$\pm=$ with or without.

* Shaded region indicates uncontrolled case series.

were often studied with Grade II tumors. These studies highlighted the much higher recurrence of AMs and MMs compared with Grade I tumors. Since the WHO 2000/2007 grading system was implemented, the literature on Grade III meningiomas has been sparse (Table 6), $1,21,23,61,68,76,87$ and therefore management decisions must rely on research using both pre-2000 and 2000/2007 WHO grading.

\section{Surgery}

Sughrue et al. performed a retrospective review of 34 patients with primary WHO Grade III meningiomas that were treated with resection (GTR, near-total resection [NTR]) and EBRT. ${ }^{76}$ Forty-seven percent of patients experienced recurrence at a mean follow-up of 6.9 years. Their 2-, 5-, and 10-year PFS rates after primary surgery were $80 \%, 57 \%$, and $40 \%$, respectively. Some patients with recurrence elected against repeat surgery, allowing the authors to compare repeat surgery versus no surgery. Their analysis demonstrated a significant survival benefit with repeat surgery compared with no repeat surgery for recurrent MMs (EBM Level 3, Grade 1C recommendation).

The important question underlying these observations is whether EOR for MMs significantly affects outcome. Durand et al. and Adeberg et al. independently demonstrated no association between EOR and outcome. ${ }^{1,21} \mathrm{MMs}$ are often brain invasive and difficult to resect completely from the adjacent brain. Indeed, Sughrue et al. actually suggested that for both primary surgery and repeat surgery, NTR may carry survival benefit over GTR. ${ }^{76}$ Taken together, despite a clear benefit of EOR per se, retrospective data on Grade III meningiomas support a maximal but cautious resection strategy and consideration of even repeat surgery for recurrence.

\section{Radiotherapy}

Only a handful of retrospective studies on MMs compared adjuvant radiotherapy versus resection alone (Table 6). Durand et al. reported that radiotherapy was associated with increased OS in MMs, and Zhao et al. reported that radiotherapy was associated with increased PFS and OS in MMs. ${ }^{21,87}$ With WHO 2000/2007 Grade III tumors constituting only $1.6 \%$ of meningiomas and the preponderance of expert opinion in favor of radiotherapy for $\mathrm{MMs},{ }^{83}$ the true efficacy of radiotherapy on WHO Grade III meningiomas is not likely to be evaluated in a random- ized fashion even with multiinstitutional efforts. However, several reports have shown a benefit with dose-escalation of radiotherapy. ${ }^{23,33,52} \mathrm{Hug}$ et al. reviewed 16 malignant meningiomas to show that conformal, high-dose radiotherapy resulted in significant improvement of local control and a survival benefit for malignant meningiomas. ${ }^{33}$ Limited studies have also reported improved outcomes with dose escalation using proton or carbon ion radiotherapy. ${ }^{11,16} \mathrm{In}$ terpretation of the data on EBRT must be taken with some caution because the majority of dose-response studies were performed prior to the WHO 2000/2007 classification. Nonetheless, together with modern studies, $1,13,21,61,68,76$ evidence supports the use of radiotherapy for Grade III meningiomas (EBM Level 3, Grade 1C recommendation).

\section{Chemotherapy}

The use of chemotherapy for MMs has mainly been limited to recurrent disease. As mentioned earlier, the population treated with chemotherapy has been a mix of patients with WHO Grade II and III meningiomas. As with AMs, the majority of case series using chemotherapy for MMs have studied the effects of hydroxyurea, imatinib, somatostatin analogs, and angiogenesis inhibitors. Hydroxyurea and imatinib have shown limited efficacy. Conversely, select trials have suggested that angiogenesis inhibitors may play a role in salvage therapy for recurrent or refractory MMs (EBM Level 2, Grade 2B recommendation) ${ }^{39,55,56,65}$ Clearly, additional studies are needed for these formidable meningiomas.

\section{Treatment Algorithm for MMs}

Based on the available literature, we suggest an algorithm for MM management (Fig. 2). The limited number of decision points and treatment options in the algorithm reflects the paucity of literature on MMs as well as the lack of effective therapies after multiple recurrences. New approaches are needed for this rare malignancy.

\section{Discussion}

Here, we have reviewed the modern literature on AMs and MMs through the lens of key clinical decision points in meningioma management, extracted outcome measures for relevant cohorts, and classified recommendations using EBM. In summary, we make EBM Level 3, Grade 1C 


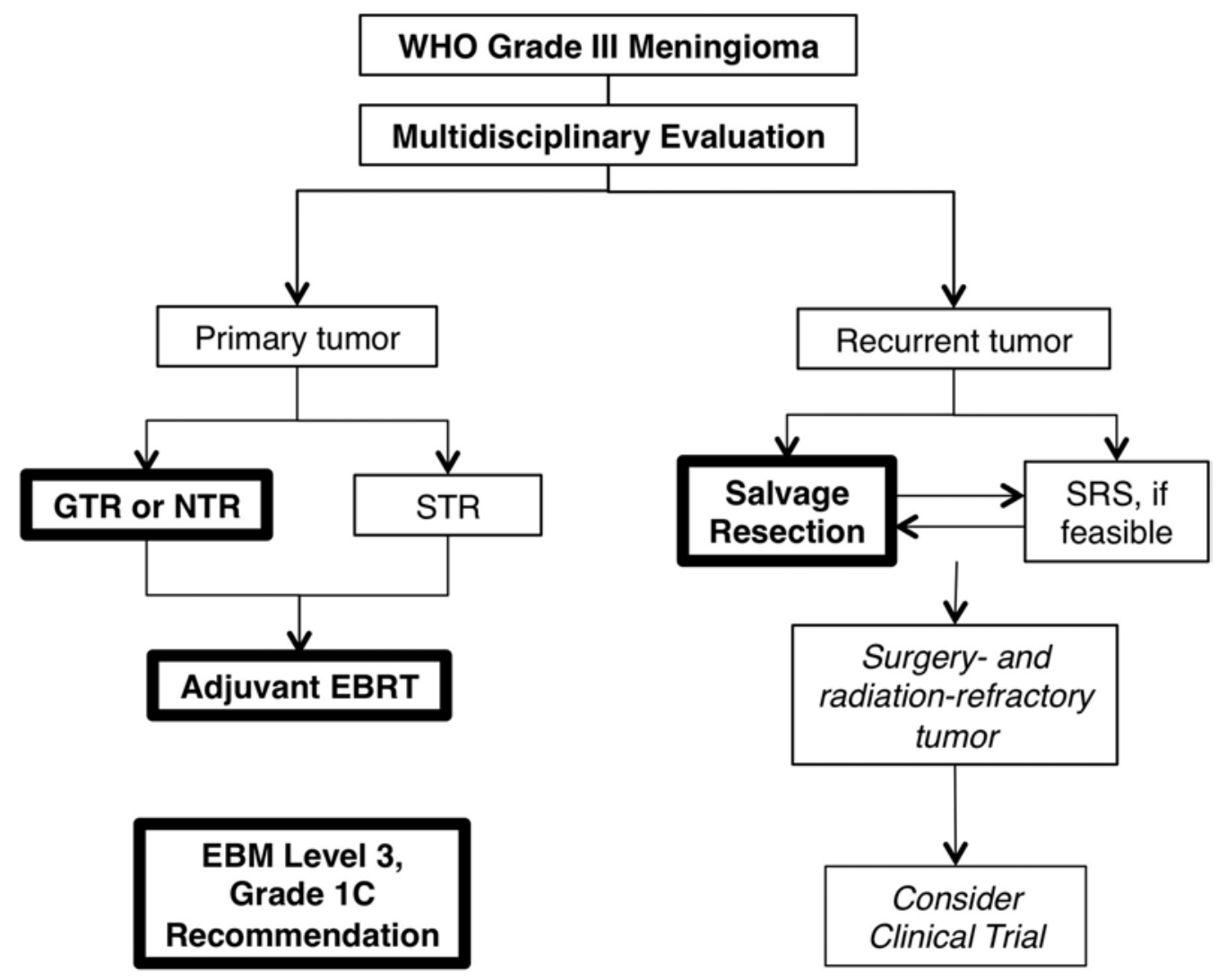

FIG. 2. Suggested algorithm for treatment of WHO Grade III meningiomas. Treatment options in bold represent EBM Level 3 , Grade $1 \mathrm{C}$ recommendations.

recommendations for the following strategies: 1) maximal safe resection of AMs and MMs; 2) active surveillance after GTR of AMs; 3) adjuvant radiation therapy after subtotal resection of AMs; and 4) adjuvant radiation therapy after resection of MMs. We have also found EBM Level 3 , Grade $2 \mathrm{C}$ recommendations for 2 intriguing strategies that require further corroboration in future studies: 1) selective radiation therapy for AMs based on the absence of histopathological necrosis; and 2) adjuvant SRS for small residual AMs after STR. It must be noted, however, that the entire body of AM and MM literature upon which this study rests is limited on multiple fronts. Notably, many studies consist of small numbers of patients with limited follow-up. Furthermore, given their retrospective nature, these studies all suffer from inhomogeneous data sets, nonrandom assignment to different management strategies, and inconsistent follow-up. As a result, the findings of this study are subject to revision pending results from ongoing prospective interventional studies. ${ }^{34,35}$

We would like to particularly emphasize a key limitation of the existing data: a lack of long-term follow-up. The average age of a patient with newly diagnosed meningioma is in the $50 \mathrm{~s},{ }^{26,78}$ and the average life expectancy in English-speaking countries is currently in the late 70s. However, the literature primarily consists of outcomes reported at 5 years. Patients with AM and MM continue to develop problems from their disease or sequelae from treatment at 10 or 20 years following initial surgery. A true understanding of the long-term, natural history of AM and MM will likely not be elucidated by recently initiated prospective, randomized studies in the near term. Instead, in the meantime, multicenter, retrospective cohort studies pooling individual patient data may be useful in the determination of effective treatment strategies. This study design has been used effectively in cardiology to determine the differential effects of treatment on subsets of patients, ${ }^{32}$ an approach that may be useful since recent AM literature suggests that subsets of tumors may respond differently to radiotherapy. ${ }^{77}$ In this regard, clinical correlation with the rapidly accumulating genetic data on meningiomas will certainly also help to tailor treatment recommendations for Grade II and III meningiomas. .14,15 $^{7}$

\section{Conclusions}

This study reviews reported management strategies and outcomes for patients with WHO Grade II and III meningiomas in an effort to develop a logical algorithm for evidence-based treatment recommendations. The evidence primarily supports safe GTR of AMs or, if GTR is not feasible, STR with adjuvant radiotherapy. A safe maximal resection should be attempted for Grade III meningiomas followed by radiotherapy, with consideration for additional surgeries following recurrence. Additional treatments may be considered in select circumstances. The treatment algorithm and recommendations regarding therapies following surgery can serve as a current guide to practicing 
neurosurgeons until prospective data from RTOG (Radiation Therapy Oncology Group) 0539 (clinical trial no. NCT00895622) becomes available.

\section{References}

1. Adeberg S, Hartmann C, Welzel T, Rieken S, Habermehl D, von Deimling A, et al: Long-term outcome after radiotherapy in patients with atypical and malignant meningiomas-clinical results in 85 patients treated in a single institution leading to optimized guidelines for early radiation therapy. Int J Radiat Oncol Biol Phys 83:859-864, 2012

2. Aghi MK, Carter BS, Cosgrove GR, Ojemann RG, AminHanjani S, Martuza RL, et al: Long-term recurrence rates of atypical meningiomas after gross total resection with or without postoperative adjuvant radiation. Neurosurgery 64:56-60, 2009

3. Aizer AA, Arvold ND, Catalano P, Claus EB, Golby AJ, Johnson MD, et al: Adjuvant radiation therapy, local recurrence, and the need for salvage therapy in atypical meningioma. Neuro Oncol 16:1547-1553, 2014

4. Attia A, Chan MD, Mott RT, Russell GB, Seif D, Bourland JD, et al: Patterns of failure after treatment of atypical meningioma with gamma knife radiosurgery. J Neurooncol 108:179-185, 2012

5. Backer-Grøndahl T, Moen BH, Torp SH: The histopathological spectrum of human meningiomas. Int J Clin Exp Pathol 5:231-242, 2012

6. Boskos C, Feuvret L, Noel G, Habrand JL, Pommier P, Alapetite $\mathrm{C}$, et al: Combined proton and photon conformal radiotherapy for intracranial atypical and malignant meningioma. Int J Radiat Oncol Biol Phys 75:399-406, 2009

7. Brastianos PK, Horowitz PM, Santagata S, Jones RT, McKenna A, Getz G, et al: Genomic sequencing of meningiomas identifies oncogenic SMO and AKT1 mutations. Nat Genet 45:285-289, 2013

8. Bruna J, Brell M, Ferrer I, Gimenez-Bonafe P, Tortosa A: Ki67 proliferative index predicts clinical outcome in patients with atypical or anaplastic meningioma. Neuropathology 27:114-120, 2007

9. Chamberlain MC: Hydroxyurea for recurrent surgery and radiation refractory high-grade meningioma. J Neurooncol 107:315-321, 2012

10. Chamoun R, Krisht KM, Couldwell WT: Incidental meningiomas. Neurosurg Focus 31(6):E19, 2011

11. Chan AW, Bernstein KD, Adams JA, Parambi RJ, Loeffler JS: Dose escalation with proton radiation therapy for highgrade meningiomas. Technol Cancer Res Treat 11:607614, 2012

12. Choi CY, Soltys SG, Gibbs IC, Harsh GR, Jackson PS, Lieberson RE, et al: Cyberknife stereotactic radiosurgery for treatment of atypical (WHO grade II) cranial meningiomas. Neurosurgery 67:1180-1188, 2010

13. Choi Y, Lim H, Jo K, Nam DH, Seol HJ, Lee JI: Efficacy of postoperative radiotherapy for high grade meningiomas. J Neurooncol 119:405-412, 2014

14. Clark VE, Erson-Omay EZ, Serin A, Yin J, Cotney J, Özduman K, et al: Genomic analysis of non-NF2 meningiomas reveals mutations in TRAF7, KLF4, AKT1, and SMO. Science 339: 1077-1080, 2013

15. Claus EB, Calvocoressi L, Greenhalgh S, Walsh K, Schildkraut J, Bondy M, et al: Genetic changes in radiation-associated meningioma. Neuro Oncol 16:iiil, 2014 (Abstract)

16. Combs SE, Kessel K, Habermehl D, Haberer T, Jäkel O, Debus J: Proton and carbon ion radiotherapy for primary brain tumors and tumors of the skull base. Acta Oncol 52:15041509,2013

17. Combs SE, Schulz-Ertner D, Debus J, von Deimling A, Hartmann C: Improved correlation of the neuropathologic clas- sification according to adapted World Health Organization classification and outcome after radiotherapy in patients with atypical and anaplastic meningiomas. Int J Radiat Oncol Biol Phys 81:1415-1421, 2011

18. Ding D, Starke RM, Kano H, Nakaji P, Barnett GH, Mathieu D, et al: Gamma knife radiosurgery for cerebellopontine angle meningiomas: a multicenter study. Neurosurgery 75:398-408, 2014

19. Dolecek TA, Propp JM, Stroup NE, Kruchko C: CBTRUS statistical report: primary brain and central nervous system tumors diagnosed in the United States in 2005-2009. Neuro Oncol 14 (Suppl 5):v1-v49, 2012

20. Du Plessis DG: Russell and Rubinstein's Pathology of Tumors of the Nervous System (7th edition). Neuropathol Appl Neurobiol 33:246-247, 2007

21. Durand A, Labrousse F, Jouvet A, Bauchet L, Kalamaridès M, Menei P, et al: WHO grade II and III meningiomas: a study of prognostic factors. J Neurooncol 95:367-375, 2009

22. Ferraro DJ, Funk RK, Blackett JW, Ju MR, DeWees TA, Chicoine MR, et al: A retrospective analysis of survival and prognostic factors after stereotactic radiosurgery for aggressive meningiomas. Radiat Oncol 9:38, 2014

23. Goldsmith BJ, Wara WM, Wilson CB, Larson DA: Postoperative irradiation for subtotally resected meningiomas. A retrospective analysis of 140 patients treated from 1967 to 1990. J Neurosurg 80:195-201, 1994 (Erratum in J Neurosurg 80:777, 1994)

24. Hammouche S, Clark S, Wong AHL, Eldridge P, Farah JO: Long-term survival analysis of atypical meningiomas: survival rates, prognostic factors, operative and radiotherapy treatment. Acta Neurochir (Wien) 156:1475-1481, 2014

25. Hanakita S, Koga T, Igaki H, Murakami N, Oya S, Shin M, et al: Role of gamma knife surgery for intracranial atypical (WHO grade II) meningiomas. J Neurosurg 119:1410-1414, 2013

26. Hardesty DA, Wolf AB, Brachman DG, McBride HL, Youssef E, Nakaji P, et al: The impact of adjuvant stereotactic radiosurgery on atypical meningioma recurrence following aggressive microsurgical resection. J Neurosurg 119:475481,2013

27. Harris AE, Lee JY, Omalu B, Flickinger JC, Kondziolka D, Lunsford LD: The effect of radiosurgery during management of aggressive meningiomas. Surg Neurol 60:298-305, 2003

28. Hasseleid BF, Meling TR, Rønning P, Scheie D, Helseth E: Surgery for convexity meningioma: Simpson Grade I resection as the goal. Clinical article. J Neurosurg 117:999-1006, 2012

29. Hawasli AH, Bagade S, Shimony JS, Miller-Thomas M, Leuthardt EC: Magnetic resonance imaging-guided focused laser interstitial thermal therapy for intracranial lesions: singleinstitution series. Neurosurgery 73:1007-1017, 2013

30. Hawasli AH, Rubin JB, Tran DD, Adkins DR, Waheed S, Hullar TE, et al: Antiangiogenic agents for nonmalignant brain tumors. J Neurol Surg B Skull Base 74:136-141, 2013

31. Heald JB, Carroll TA, Mair RJ: Simpson grade: an opportunity to reassess the need for complete resection of meningiomas. Acta Neurochir (Wien) 156:383-388, 2014

32. Hlatky MA, Boothroyd DB, Bravata DM, Boersma E, Booth J, Brooks MM, et al: Coronary artery bypass surgery compared with percutaneous coronary interventions for multivessel disease: a collaborative analysis of individual patient data from ten randomised trials. Lancet 373:1190-1197, 2009

33. Hug EB, Devries A, Thornton AF, Munzenride JE, Pardo FS, Hedley-Whyte ET, et al: Management of atypical and malignant meningiomas: role of high-dose, 3D-conformal radiation therapy. J Neurooncol 48:151-160, 2000

34. Jenkinson MD, Weber DC, Haylock BJ, Mallucci CL, Zakaria R, Javadpour M: Atypical meningoma: current management dilemmas and prospective clinical trials. J Neurooncol 121:1-7, 2014 
35. Jenkinson MD, Weber DC, Haylock BJ, Mallucci CL, Zakaria R, Javadpour M: Radiotherapy versus observation following surgical resection of atypical meningioma (the ROAM trial). Neuro Oncol 16:1560-1561, 2014 (Letter)

36. Jethwa PR, Barrese JC, Gowda A, Shetty A, Danish SF: Magnetic resonance thermometry-guided laser-induced thermal therapy for intracranial neoplasms: initial experience. Neurosurgery 71:133-145, 2012

37. Jo K, Park HJ, Nam DH, Lee JI, Kong DS, Park K, et al: Treatment of atypical meningioma. J Clin Neurosci 17:1362-1366, 2010

38. Kaley T, Barani I, Chamberlain M, McDermott M, Panageas $\mathrm{K}$, Raizer J, et al: Historical benchmarks for medical therapy trials in surgery- and radiation-refractory meningioma: a RANO review. Neuro Oncol 16:829-840, 2014

39. Kaley TJ, Wen P, Schiff D, Ligon K, Haidar S, Karimi S, et al: Phase II trial of sunitinib for recurrent and progressive atypical and anaplastic meningioma. Neuro Oncol 17:116121,2015

40. Kano H, Takahashi JA, Katsuki T, Araki N, Oya N, Hiraoka $\mathrm{M}$, et al: Stereotactic radiosurgery for atypical and anaplastic meningiomas. J Neurooncol 84:41-47, 2007

41. Kaur G, Sayegh ET, Larson A, Bloch O, Madden M, Sun MZ, et al: Adjuvant radiotherapy for atypical and malignant meningiomas: a systematic review. Neuro Oncol 16:628-636, 2014

42. Kinjo T, al-Mefty O, Kanaan I: Grade zero removal of supratentorial convexity meningiomas. Neurosurgery 33:394399, 1993

43. Kleihues P, Burger PC, Scheithauer BW: The new WHO classification of brain tumours. Brain Pathol 3:255-268, 1993

44. Kleihues P, Cavenee WK: Pathology and Genetics of Tumours of the Nervous System. Lyon: IARC Press, 2000

45. Komotar RJ, Iorgulescu JB, Raper DM, Holland EC, Beal $\mathrm{K}$, Bilsky $\mathrm{MH}$, et al: The role of radiotherapy following gross-total resection of atypical meningiomas. J Neurosurg 117:679-686, 2012

46. Lee KD, DePowell JJ, Air EL, Dwivedi AK, Kendler A, McPherson CM: Atypical meningiomas: is postoperative radiotherapy indicated? Neurosurg Focus 35(6):E15, 2013

47. Louis DN, Ohgaki H, Wiestler OD, Cavenee WK, Burger PC, Jouvet A, et al: The 2007 WHO classification of tumours of the central nervous system. Acta Neuropathol 114:97-109, 2007

48. Mair R, Morris K, Scott I, Carroll TA: Radiotherapy for atypical meningiomas. J Neurosurg 115:811-819, 2011

49. Marcus HJ, Price SJ, Wilby M, Santarius T, Kirollos RW: Radiotherapy as an adjuvant in the management of intracranial meningiomas: are we practising evidence-based medicine? Br J Neurosurg 22:520-528, 2008

50. Mattozo CA, De Salles AA, Klement IA, Gorgulho A, McArthur D, Ford JM, et al: Stereotactic radiation treatment for recurrent nonbenign meningiomas. J Neurosurg 106:846-854, 2007

51. Mawrin C, Perry A: Pathological classification and molecular genetics of meningiomas. J Neurooncol 99:379-391, 2010

52. Milosevic MF, Frost PJ, Laperriere NJ, Wong CS, Simpson WJ: Radiotherapy for atypical or malignant intracranial meningioma. Int J Radiat Oncol Biol Phys 34:817-822, 1996

53. Modha A, Gutin PH: Diagnosis and treatment of atypical and anaplastic meningiomas: a review. Neurosurgery 57:538 550,2005

54. Nakamura M, Roser F, Michel J, Jacobs C, Samii M: The natural history of incidental meningiomas. Neurosurgery 53:62-71, 2003

55. Nayak L, Iwamoto FM, Rudnick JD, Norden AD, Lee EQ, Drappatz J, et al: Atypical and anaplastic meningiomas treated with bevacizumab. J Neurooncol 109:187-193, 2012

56. Norden AD, Raizer JJ, Abrey LE, Lamborn KR, Lassman $\mathrm{AB}$, Chang SM, et al: Phase II trials of erlotinib or gefi- tinib in patients with recurrent meningioma. J Neurooncol 96:211-217, 2010

57. Olar A, Wani KM, Sulman EP, Mansouri A, Zadeh G, Wilson $\mathrm{CD}$, et al: Mitotic index is an independent predictor of recurrence-free survival in meningioma. Brain Pathol [epub ahead of print], 2014

58. Oya S, Kawai K, Nakatomi H, Saito N: Significance of Simpson grading system in modern meningioma surgery: integration of the grade with MIB-1 labeling index as a key to predict the recurrence of WHO Grade I meningiomas. $\mathbf{J}$ Neurosurg 117:121-128, 2012 (Erratum in J Neurosurg 117:806, 2012)

59. Park HJ, Kang HC, Kim IH, Park SH, Kim DG, Park CK, et al: The role of adjuvant radiotherapy in atypical meningioma. J Neurooncol 115:241-247, 2013

60. Pearson BE, Markert JM, Fisher WS, Guthrie BL, Fiveash JB, Palmer CA, et al: Hitting a moving target: evolution of a treatment paradigm for atypical meningiomas amid changing diagnostic criteria. Neurosurg Focus 24(5):E3, 2008

61. Pollock BE, Stafford SL, Link MJ, Garces YI, Foote RL: Stereotactic radiosurgery of World Health Organization grade II and III intracranial meningiomas: treatment results on the basis of a 22-year experience. Cancer 118:1048-1054, 2012

62. Preusser M, Hassler M, Birner P, Rudas M, Acker T, Plate $\mathrm{KH}$, et al: Microvascularization and expression of VEGF and its receptors in recurring meningiomas: pathobiological data in favor of anti-angiogenic therapy approaches. Clin Neuropathol 31:352-360, 2012

63. Preusser M, Spiegl-Kreinecker S, Lötsch D, Wöhrer A, Schmook M, Dieckmann K, et al: Trabectedin has promising antineoplastic activity in high-grade meningioma. Cancer 118:5038-5049, 2012

64. Quiñones-Hinojosa A, Raza SM: Controversies in NeuroOncology: Best Evidence Medicine for Brain Tumor Surgery. New York: Thieme, 2013

65. Raizer JJ, Grimm SA, Rademaker A, Chandler JP, Muro K, Helenowski I, et al: A phase II trial of PTK787/ZK 222584 in recurrent or progressive radiation and surgery refractory meningiomas. J Neurooncol 117:93-101, 2014

66. Reardon DA, Norden AD, Desjardins A, Vredenburgh JJ, Herndon JE II, Coan A, et al: Phase II study of Gleevec ${ }^{\circledR}$ plus hydroxyurea (HU) in adults with progressive or recurrent meningioma. J Neurooncol 106:409-415, 2012

67. Rogers L, Gilbert M, Vogelbaum MA: Intracranial meningiomas of atypical (WHO grade II) histology. J Neurooncol 99:393-405, 2010

68. Rosenberg LA, Prayson RA, Lee J, Reddy C, Chao ST, Barnett GH, et al: Long-term experience with World Health Organization grade III (malignant) meningiomas at a single institution. Int J Radiat Oncol Biol Phys 74:427-432, 2009

69. Santacroce A, Walier M, Régis J, Liščák R, Motti E, Lindquist C, et al: Long-term tumor control of benign intracranial meningiomas after radiosurgery in a series of 4565 patients. Neurosurgery 70:32-39, 2012

70. Sheehan JP, Starke RM, Kano H, Kaufmann AM, Mathieu D, Zeiler FA, et al: Gamma Knife radiosurgery for sellar and parasellar meningiomas: a multicenter study. J Neurosurg 120:1268-1277, 2014

71. Shekelle PG, Woolf SH, Eccles M, Grimshaw J: Developing clinical guidelines. West J Med 170:348-351, 1999

72. Sindou M, Wydh E, Jouanneau E, Nebbal M, Lieutaud T: Long-term follow-up of meningiomas of the cavernous sinus after surgical treatment alone. J Neurosurg 107:937-944, 2007

73. Smith SJ, Boddu S, Macarthur DC: Atypical meningiomas: WHO moved the goalposts? Br J Neurosurg 21:588-592, 2007

74. Sughrue ME, Kane AJ, Shangari G, Rutkowski MJ, McDermott MW, Berger MS, et al: The relevance of Simpson Grade 
I and II resection in modern neurosurgical treatment of World Health Organization Grade I meningiomas. J Neurosurg 113:1029-1035, 2010

75. Sughrue ME, Rutkowski MJ, Aranda D, Barani IJ, McDermott MW, Parsa AT: Factors affecting outcome following treatment of patients with cavernous sinus meningiomas. J Neurosurg 113:1087-1092, 2010

76. Sughrue ME, Sanai N, Shangari G, Parsa AT, Berger MS, McDermott MW: Outcome and survival following primary and repeat surgery for World Health Organization Grade III meningiomas. J Neurosurg 113:202-209, 2010

77. Sun SQ, Cai C, Murphy RK, DeWees T, Dacey RG, Grubb $\mathrm{RL}$, et al: Management of atypical cranial meningiomas, part 2: predictors of progression and the role of adjuvant radiation after subtotal resection. Neurosurgery 75:356-363, 2014

78. Sun SQ, Kim AH, Cai C, Murphy RK, DeWees T, Sylvester $\mathrm{P}$, et al: Management of atypical cranial meningiomas, part 1: predictors of recurrence and the role of adjuvant radiation after gross total resection. Neurosurgery 75:347-355, 2014

79. van Alkemade H, de Leau M, Dieleman EM, Kardaun JW, van Os R, Vandertop WP, et al: Impaired survival and longterm neurological problems in benign meningioma. Neuro Oncol 14:658-666, 2012

80. Vranic A, Popovic M, Cör A, Prestor B, Pizem J: Mitotic count, brain invasion, and location are independent predictors of recurrence-free survival in primary atypical and malignant meningiomas: a study of 86 patients. Neurosurgery 67:1124-1132, 2010

81. Wang YC, Chuang CC, Wei KC, Hsu YH, Hsu PW, Lee ST, et al: Skull base atypical meningioma: long term surgical outcome and prognostic factors. Clin Neurol Neurosurg 128:112-116, 2015

82. Wen PY, Yung WK, Lamborn KR, Norden AD, Cloughesy TF, Abrey LE, et al: Phase II study of imatinib mesylate for recurrent meningiomas (North American Brain Tumor Consortium study 01-08). Neuro Oncol 11:853-860, 2009
83. Willis J, Smith C, Ironside JW, Erridge S, Whittle IR, Everington $\mathrm{D}$ : The accuracy of meningioma grading: a 10-year retrospective audit. Neuropathol Appl Neurobiol 31:141149,2005

84. Wright JG, Swiontkowski MF, Heckman JD: Introducing levels of evidence to the journal. J Bone Joint Surg Am 85A:1-3, 2003

85. Yang SY, Park CK, Park SH, Kim DG, Chung YS, Jung HW: Atypical and anaplastic meningiomas: prognostic implications of clinicopathological features. J Neurol Neurosurg Psychiatry 79:574-580, 2008

86. Yano S, Kuratsu J: Indications for surgery in patients with asymptomatic meningiomas based on an extensive experience. J Neurosurg 105:538-543, 2006

87. Zhao P, Hu M, Zhao M, Ren X, Jiang Z: Prognostic factors for patients with atypical or malignant meningiomas treated at a single center. Neurosurg Rev 38:101-107, 2015

\section{Author Contributions}

Conception and design: all authors. Acquisition of data: all authors. Analysis and interpretation of data: all authors. Drafting the article: Kim, Sun, Hawasli. Critically revising the article: all authors. Reviewed submitted version of manuscript: all authors. Approved the final version of the manuscript on behalf of all authors: Kim. Statistical analysis: Kim, Sun, Hawasli. Administrative/technical/material support: Kim, Sun, Hawasli. Study supervision: Kim, Sun, Hawasli.

\section{Correspondence}

Albert H. Kim, Department of Neurological Surgery, Washington University School of Medicine, 660 S. Euclid Ave., Campus Box 8057, St. Louis, MO 63110. email: kima@wudosis.wustl.edu. 